\title{
Blockchain in air cargo: challenges of new World
}

\author{
Irina Poleshkina ${ }^{1 *}$ \\ ${ }^{1}$ Moscow State Technical University of Civil Aviation, Kronshtadtskiy Blvd. 20, Moscow, Russia
}

\begin{abstract}
The last years' experience of functioning during the COVID-19 pandemic has shown that digital solutions can significantly increase the efficiency of business operational processes. This study focuses on the implementation of digital technologies at the airports to optimize information and financial flows, that are required for the air cargo transportation. The study was carried out based on the analysis of technological schedules of airports and airlines for cargo handling. As a result of this study, we have identified the main problematic operations leading to an increase in the time spent by cargo at the airports. The article examines and summarizes the world practice of using blockchain technology to manage information and financial flows in air cargo. The article has developed a model for the implementation of these technologies in the air cargo industry on the basis of a single blockchain platform. This model allows making optimal use of available airport resources in order to minimize service delays. It solves the main problem of creating the transparency of the information exchange between all air cargo transportation participants.
\end{abstract}

Air transportation plays very important role in modern economy. According to IATA, about $35 \%$ of the turnover of international supply chains in value terms and $1 \%$ in physical volume is carried out by air [1]. In 2019, worldwide airfreight traffic rose to 61,2 million metrics tons [2]. This is due to the high added value of goods, transported by air. For example, these are electronic devices, fashion clothes, jewelry, luxury cars, exotic fruits and vegetables, live animals, e-commerce goods, pharmaceuticals etc. The main advantage of air transport is the speed of delivery. Most of the time during air delivery, goods are at the airport of departure and destination. This is mainly caused by the need to follow the airport's formalities, such as security inspection, registration and verification of documents, customs clearance of goods, veterinary and phytosanitary checks, packaging, labeling, etc. [3]. High costs and extended times are the crucial challenges for air freight [4]. To increase the attractiveness of air transport for the international supply chains, it is necessary to reduce the total delivery time. Since the flight time is a fixed value, the delivery time can be reduced by optimizing the time spent by cargo at the airports. Recommendations for facilitating airport formalities are spelled out in Annex 9 of the Convention on International Civil Aviation Doc. 7300. According to the convention, it is possible to achieve a reduction

\footnotetext{
* Corresponding author: ipoleshkina@mstuca.aero
} 
in the operational time for handling cargo at the airports by optimizing the processing, verification and exchange of documents. Digitalization on airfreight took place much later than that on the passenger's side [2]. Last years' experience of functioning in time of the COVID-19 pandemic has shown that digital solutions can significantly increase the efficiency of the business operational processes.

This study focuses on the implementation of digital technologies at the airports to optimize information and financial flows, required for the transportation of goods.

Currently, digital technologies are being implemented in all areas of the airport [5]. Airports are working towards digitalization, launching dedicated apps (like Changi, Incheon, Schiphol, Heathrow, Frankfurt, Munich, Zurich or Copenhagen Airport) and covering key areas where digitalization has the greatest impact: operations, security, passengers and retail [6]. A digital solution to simplify the document flow at the airport is the E-Freight system. The E-Freight system is an international standard for paperless clearance and support of air cargo transportation, recommended by the International Air Transport Association (IATA) within the framework of the IATA international industry program "Simplifying the Business". The use of this digital solution has reduced the paperwork processing times for air cargo transportation by 50\%. In 2019 IATA developed Smart Facility program to improve the transparency on service levels at cargo handling facilities. The program reduces audit frequency, complexity, and costs and makes information available on ONE Source, a new online platform. Through ONE Source, shippers can find business partners for their needs through full disclosure on everything from temperature-controlled rooms to IATA certifications [7]. A digital solution to simplify financial flows is the electronic settlement system.

Verification whether the accompanying documents are correct and the goods are marked appropriately, however, as well as controlling the mutual settlements between the participants in the air transportation is still a problem. Case study of the use of the blockchain technology in the supply chain management has shown that the blockchain can be a digital solution to simplify these processes [8-10].

\section{Methods of the research}

The study was carried out based on the analysis of technological schedules of the airports and airlines for cargo handling. As a result of the study, we have identified the main problematic operations, leading to an increase in the time spent by cargo at the airports. For the study we used data from interviews with the representatives of the cargo terminals Moscow-Cargo, Tolmachevo in Novosibirsk and Pulkovo in St. Petersburg. We have also used data from IATA, ICAO (International Civil Aviation Organization), TIACA (The International Air Cargo Association), FIATA (International Federation of Freight Forwarder Association), WCO (World Customs Organisation), ACA (Airport Council Association), ACI (Airports Council International). The aim of this research is to find technologies to optimize the operations of processing information and financial flows.

The article examines and summarizes the world practice of using the blockchain technology to manage information and financial flows in air cargo. It discusses the experience of the blockchain technology use for managing the supply chain of perishable goods, to control the maintenance operations and mutual settlements between the air cargo stakeholders. The article proposes a system for the introduction of the blockchain technology in combination with the Internet of Things and Smart Contracts technologies into the logistics operational processes of handling cargo of airlines and airports, based on the study of the best practices. The article depicts a scheme for the implementation of these technologies in the air cargo industry on the basis of a single blockchain platform. 


\section{Information and financial flows of cargo transportation by air}

The air cargo industry includes large numbers of stakeholders, among them are airlines, airports, customs, ground and cargo handling companies, shippers and consignees. Airfreight shipments generate up to 30 different documents. Paperwork and documents verification, booking, tracking and tracing is done with the involvement of manual verification. The use of the E-freight technology allows the reduction of the documents exchange times between all stakeholders during the organization of the air cargo transportation.

The most time-consuming operation with cargo when using E-Freight at the cargo terminal is checking the correctness of filling out documents especially electronic Air Waybills (eAWB), marking and certificates of origin and compliance. For example, the period for customs clearance and phytosanitary inspection of a consignment of fruit at the Moscow-Cargo terminal can be up to three days [8]. IATA standard defines a time limit for cargo handling at the airport within 48 hours [11].

Organization of epy E-freight documents flow between all participants in air cargo transportation is shown in the figure 1 .

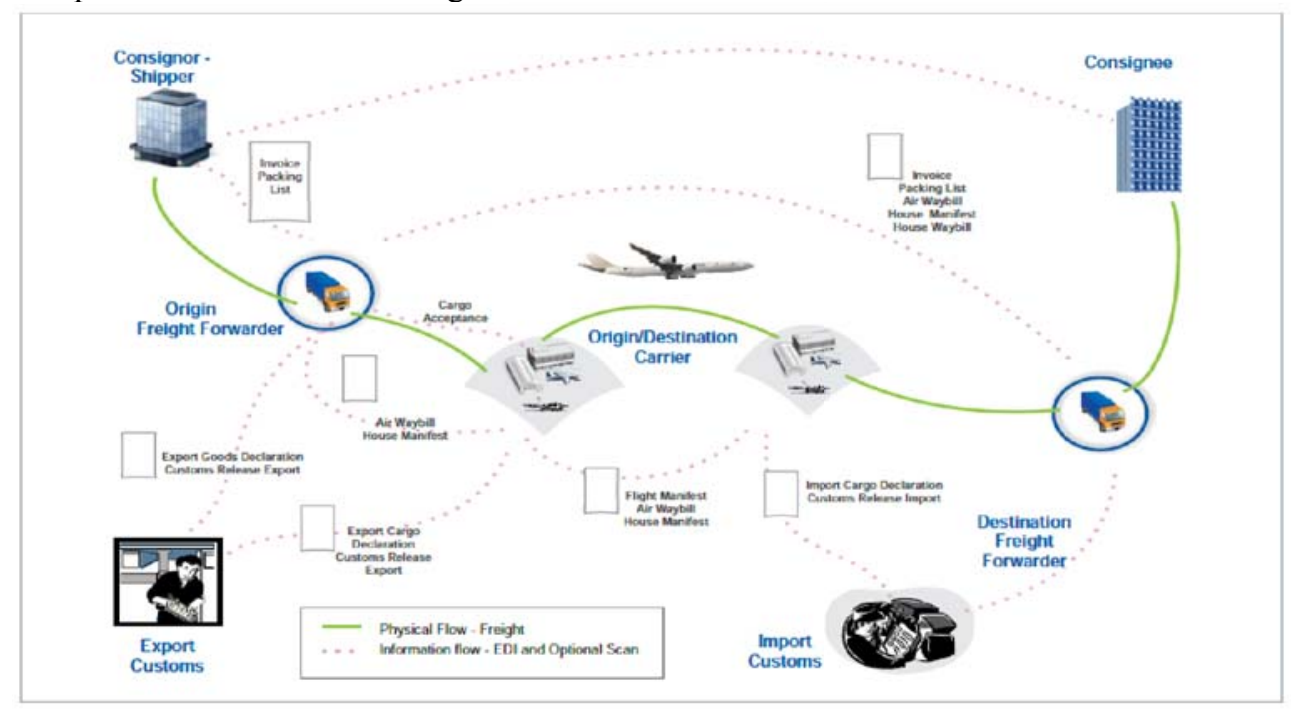

Fig. 1. Electronic workflow organization with synchronization of electronic freight and registration of import documents according to WCO recommendations

Blockchain technology can be used to simplify the process of verifying certificates of origin and compliance. The use of this technology could reduce time required for verification, save money and prevent fraud. Blockchain is a multifunctional and multi-tier information technology that has distributed storage and facilitates the accounting of the various assets and transactions in a business network. The blockchain was created in 2008 to support the Bitcoin cryptocurrency with a distributed ledger system that can be anonymous. Each deal or transaction is recorded and added to the distributed database chain as a new fragment, which is manually assigned a unique multivalued numeric cipher. Every transaction is verified by multiple users and their systems, every transaction is logged, and all activity is public. This makes certain the supply chain cannot be fraudulent because every step is verified by the entire ecosystem of checks and balances. The use of blockchain in aviation could make it possible to verify the origin and legitimacy of goods accepted for transportation. For example, Blockchain could check whether that particular mango, flying from Ecuador to Russia, is $100 \%$ certified. This technology with eAWB 
allows Quick Drop Off, reduces waiting time for the customers and manual transactions at the counter. According to experts, in the near future, a typical supply chain will be controlled through the generation of 35 zeta-bytes of information [12]. Blockchain solves the problem of reducing the volume of information exchange due to distributed data storage and increases transparency of the shipments.

Another important problem in airfreight is the electronic booking of carrying capacities and settlements. In airfreight the booking platform FGX was founded in 2000. Digitalization of booking passenger air tickets has occurred much faster than air cargo, as well as mutual settlements. The delay in digitalization of the air freight is explained by the complexity of this process and a large number of stakeholders. The enhancement of the transportation booking service for shippers can be achieved by the provision of the air freight booking through the backend system of the forwarders, faster acceptance and delivery process. It could be based on the automatically pre-checked data or the virtual integration of additional service from others providers like customs brokerage in one seamless booking flow [2]. Booking cargo capacity includes three steps:

Reservation of the goods cargo capacity only after coordination with the carrier the possibility of this cargo type transportation (documents: air waybill, safety declaration);

Passing through phytosanitary/veterinary control (documents: phytosanitary/veterinary certificate), if sending plants from the territory under quarantine, you must obtain a permission to send an individual shipment and quarantine documents; [8].

Obtaining Customs permit for cargo transportation (documents: customs declaration)

Acceleration of data verification in electronic booking can also be achieved through the use of the blockchain technology.

Another labor-intensive process in the air cargo transportation is the mutual settlements among various entities in aviation industry. Air cargo transportation is accompanied by financial settlements between airports, airlines, aircraft ground handlers, airport cargo handlers, forwarders, logistics companies and general agents for the sale of freight. Agents collect freight charges from shippers to pay to the carriers. Carriers then produce invoices to their agents for these sales. Each carrier prepares an invoice to each agent individually. The sheer number of invoices and reports must be checked and consolidated, payments have to be made individually. To automate the mutual settlements of airlines Cargo Account Settlement System (CASS) was created by IATA. This system allows cargo agents to conclude a single contract with IATA as an authorized representative of all airlines instead of several contracts with different airlines. This system minimizes the need for multiple payments by consolidating them into a single transaction. Agents pay a single amount representing all payments due to all carriers, while carriers receive only one payment that consists of payments from all agents. Using blockchain in this system could enhance the transparency of the mutual settlements. Blockchain technology could generate a unique code for each transportation and the payment for it. Integrating blockchain with a single data platform for all air cargo stakeholders could increase the speed and transparency of all transactions. In the first phase it is important to introduce a blockchain-based bill of landing. A combination of the blockchain technology and smart contracts in a unified system of mutual settlements of air cargo participants could not only increase transparency, but also automate this process.

During the organization of the air cargo transportation, in addition to the incoming financial flow from the airline's cargo sales agents, there is an outgoing financial flow from airlines to the airport ground and cargo handlers. Airport ground handlers in some cases perform operational maintenance of aircrafts. Airlines need not only to control the financial flows, but also have a transparent system for filling out the maintenance logbook in relations with the ground handlers. The transparency of the aircraft logbook helps federal 
agencies to assign an airworthiness score for the aircraft. Incomplete maintenance history affects the aircraft's safety rating and eventually decreases its market value [13]. Using blockchain technology to register and store records of aircraft maintenance could make this process more transparent and protect against loss and errors in records.

\section{Case studies of using Blockchain in logistics}

Blockchain technology is successfully applied in various areas of logistics. Maersk is collaborating with IBM to create a unified supply chain service platform for maritime transport. It reduced the administrative costs by $15 \%$ of the cost of goods shipped. At the next stage, the system was integrated with the radio frequency identification system using the Internet of Things (IoT) technology in order to generate a unified information database of the logistics network. In addition, the company uses GPS container marking systems to monitor and control their movement through transport hubs along the entire delivery route.

Blockchain is used in ports [14]. For example, the port of Hamburg obliges all companies to connect to a single information system using blockchain. Singapore Maritime and Port Authority launched Smart Port Challenge systems in 2017 to improve the efficiency of maritime logistics of delivery goods to the Port of Rotterdam [15].

Blockchain technology is used to control food safety in the supply chain of perishable products. Walmart, Unilever, Nestle and others are collaborating with IBM to develop a traceability system across the entire supply chain and food disease control, based on blockchain [16].

The blockchain technology is already widely used in aviation [17,18]. According to Lufthansa, a promising area for using blockchain technology is tracking the supply of aviation components. Samsung uses this technology to track its aviation supply chain. In 2017, British Airways collaborated with Heathrow, Miami and Geneva airports to study the use of the Blockchain technology. This study demonstrates the effectiveness of this technology in organizing the secure exchange of information [19]. Cathay Pacific uses blockchain to control container freight traffic [20]. In 2018, SITA launched the Aviation Blockchain Sandbox platform for Distributed Ledger Technology (DLT) application development.

Blockchain has great potential for tracking multimodal shipments [21]. Thus, blockchain technology allows to achieve trust between the participants of the aviation market, to facilitate cooperation and collaboration among organizations and simplify many data verification operations [22].

To work with a single blockchain platform, a system of "smart contracts" was developed, which implies encoding of a transaction only if it is approved by all its participants using a "signature share". To access the block, it is necessary to register all designated keys that have "signature shares" of this transaction [23,24]. Smart contract is a computer protocol designed to facilitate the verification negotiation or execution of contracts digitally without the involvement of the third parties, such as a notary, a broker, etc. Smart contract automatically ensures the fulfillment of the contractual obligations [25]. It can automatically send payment to the supplier as soon as the shipment is delivered. Smart contracts have huge potential to efficiently maintain aircraft maintenance records, validate crew certificates, and verify the ground handler operations at the airport [4].

\section{Proposals for the use of blockchain in air cargo}

Based on the results of the study, we propose the following directions for the implementation of the blockchain technology in air cargo transportation: monitoring and 
control supply chain logistic; electronic booking cargo capacities; mutual settlements between all participants of the air cargo transportation and record of ground handler operations, Figure 2.

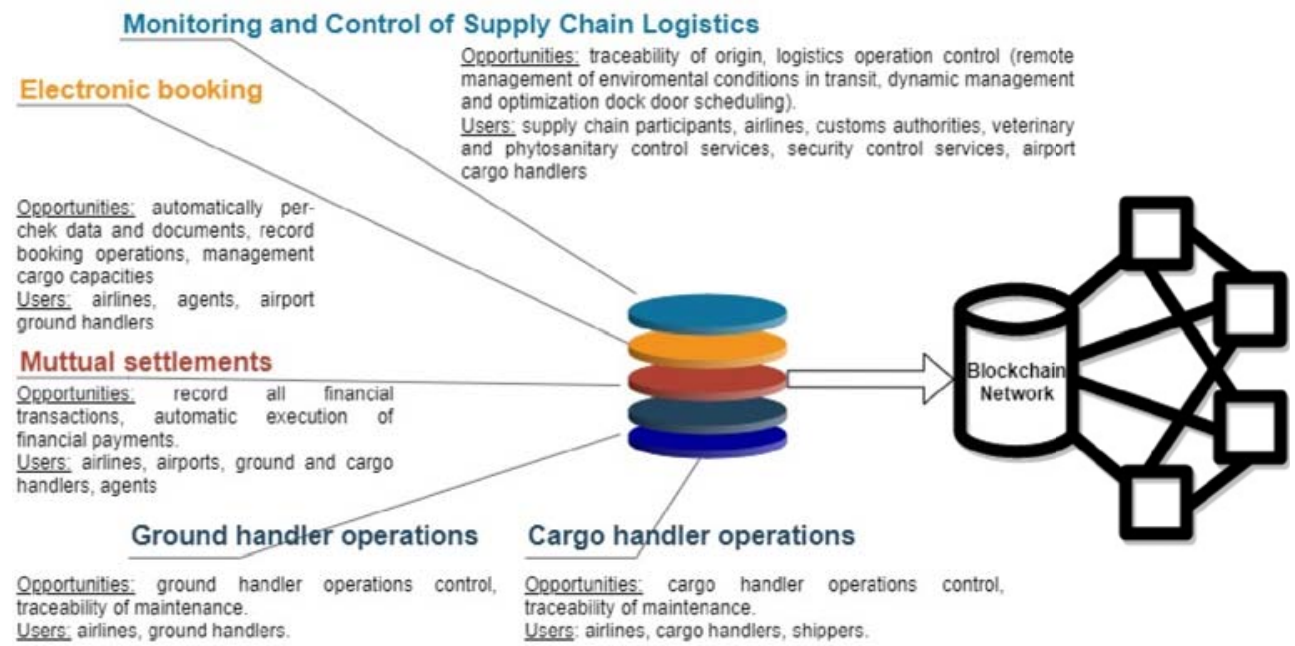

Fig. 2. Opportunities of using blockchain technology in air cargo.

It is advisable to supplement the use of the blockchain technology for supply chain management with sensors to monitor the location and condition of the transported cargo. To process information coming from sensors for monitoring the location and condition of the cargo, it is necessary to use the Internet of Things technology (IoT). The combination of blockchain technology and the IoT allows not only to control supply chains but also to fully manage them [26]. Sensors collect data such as the location, temperature, humidity and condition of the items inside the shipping package of cargo at a particular point of time. The collected data is stored on a server accessible at different stages. The blockchain technology allows to fix information about every displacement of cargo in the cloud systems by means of creating of a corresponding note [27,28]. A distributed ledger makes these recorders safe. The availability of information on the origin of goods simplifies the procedure for customs clearance of goods, verification of markings and other documents.

The system of the electronic air capacity booking, mutual settlements and control of handling operations at the airports works in a similar way. The accuracy and reliability of information guarantees the purity and correctness of the transaction in the implementation of these operations. The simultaneous use of the blockchain technology, the Internet of Things and the Smart Contracts on the same platform simplifies the procedure for making managerial decisions and automates the fulfillment of the financial obligations. The model of interaction between air cargo participants using the smart contract system is on Figure 3. 


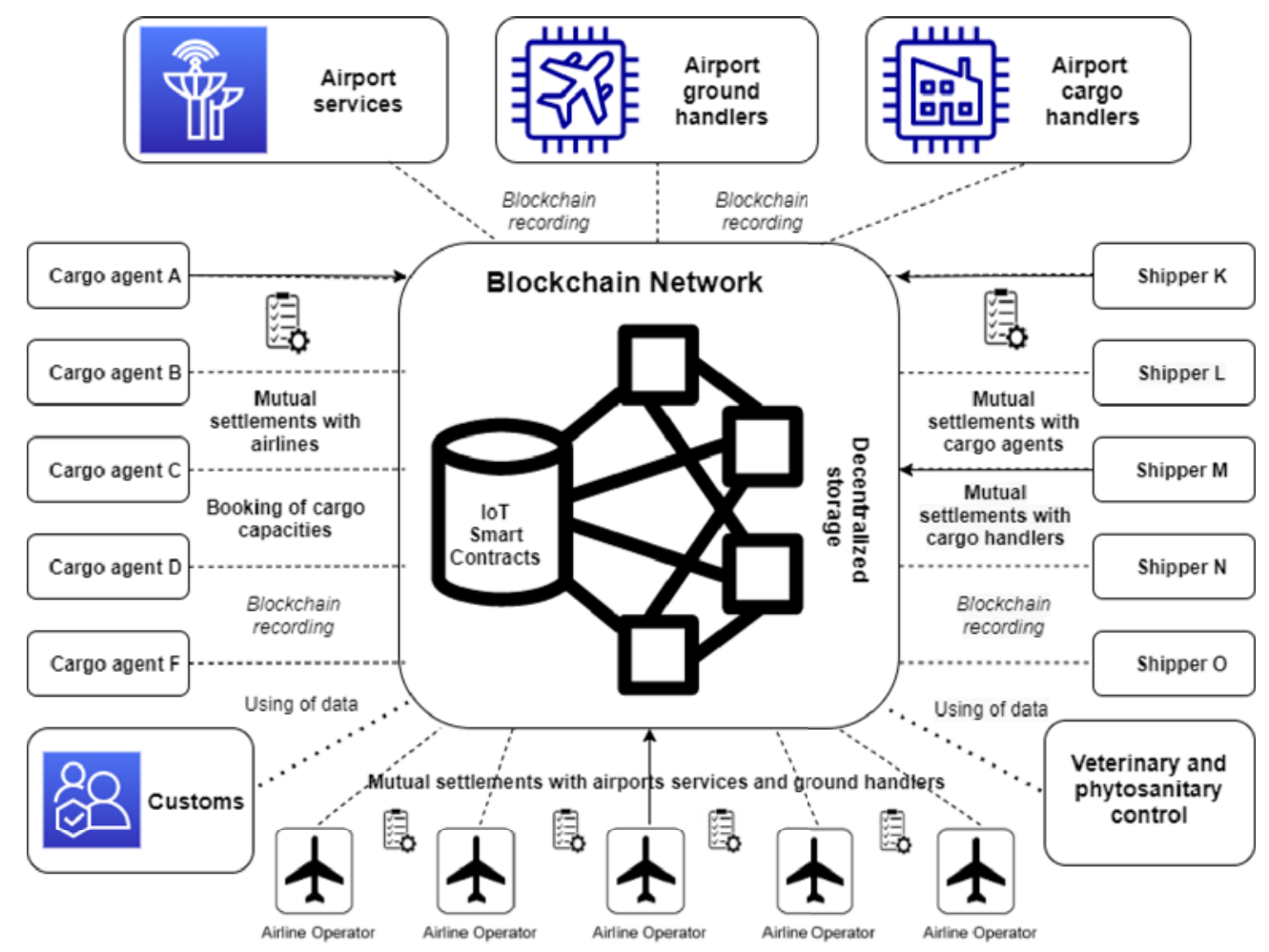

Fig. 3. Blockchain, Internet of Things and Smart contract technologies in air cargo industry

The use of the blockchain technology in combination with the IATA Cargo Account Settlement System significantly reduces the time required for the implementation of financial transactions between participants in air cargo. According to the estimates of the IBM Corporation, as soon as the blockchain technology is implemented by the majority of market participants, shippers should be able to reduce the actual costs of physical transportation by about $20 \%$. This can be achieved by filtering-out the unreliable carriers and eliminating the risks of cargo damage throughout the supply chain [29], as well as the abandonment of the insolvent shippers. In the face of increasing airport congestion, it is very important to make an optimal use of the available airport resources in order to minimize the service delays. Efficiency in the use of the airport resources depends on the transparency of the information exchange between stakeholders in the aviation industry such as ground services, air traffic control services dispatchers and airport operators [30].

\section{References}

1. Rodrigue J-P, The Geography of Transport Systems, 5 Ed.

(New York: Routledge) 456 p. (2020)

2. Wurst S, Graf L (eds.) Disruptings Logistics, Future of Bussiness and Finence (Springer Naturel: Switzerland), (2021)

3. Tozi L A, Muller C The Viability of Air Transportation for Perishable Agricultural Produce. Journal of the Brazilian Air Transportation Research Society, 2, 2, pp. 83-96. (2006) 
4. Raja W A, Khaled S, Raja J, Haya R H, Ibrar Y, Mohammed O. The Role of Blockchain Technology in Aviation Industry IEEE Aerospace and Electronic Systems Magazine

5. Zaharia S E, Pietrianu C V Challenges in airport digitl transformation Trans. Res. Pros. 35, pp. 90-99. (2018)

6. Gardy A, Canada R Digital trends \& opportunities for Airports, ACI-NA World Annual Conference. (2016)

7. Juniac A Intarnational Air Transport Association Annual Review 76th Annual General Meeting (Amsterdam). (2020)

8. Unny R B, Lal B Blockchain in supply chain management. IFIP AICT 617, pp. 149158. (2020)

9. Poleshkina I O Use of blockchain technology as supply chain management system involving air transport Civil Aviation High Thechnologies (2020)

10. Poleshkina I O Transportation of perishable goods by air: handling problems at Russian airports Civil Aviation High Thechnologies (2020)

11. Pelletier W, Chau K.V. and Bucklin R.A. Analysis of air cargo temperature during transportation operations Transactions of the ASABE 61 (2), pp. 723-732. (2018)

12. Tien J M Internet of connected ServGoods: Considerations, consequences and concerns J. Syst. Sci. Syst. Eng. 24, pp. 130-167.(2015)

13. Hasan H, AlHadhrami E, AlDhaheri A, Salah K, Jayaraman R Smart contract-based approach for efficient shipment management Comp. \& Ind. Eng. 136, pp. 149-159. (2019)

14. Gausdal A H, Czachorowski K V, Solesvik M Z Applying Blockchain Technology: Evidence from Norwegian Companies Sustainability, 10, (2018)

15. Lim J New opportunities for start-ups in the maritime sector. MPA's Smart Port Challenge. In Catalyses Maritime Industry towards Greater Innovation and Digitalisation (Maritime and Port Authority of Singapore (MPA): Singapore). (2017)

16. Amin Md R, Zuhairi M F, Saadat Md N. Enhanced Blockchain Transaction: A Case of Food Supply Chain Management J. of Engineering and Applied Sciences, 15, pp. 99106. (2020)

17. Hinsch M, Industrielles Luftfahrtmanagement: Technik und Organisation luftfahrttechnischer Betriebe 3rd ed. (Berlin, Germany: Springer Vieweg). (2017)

18. Goudarzi H, Martin J, Warren S, IATA White paper: Blockchain in Aviation. (2018)

19. Schyga J, Hinckeldeyn J, Kreutzfeldt J. Prototype for a permissioned blockchain in aircraft MRO Artificial Intelligence and Digital Transformation in Supply Chain Management: Innovative Approaches for Supply Chains. Proceedings of the Hamburg International Conference of Logistics (HICL), Vol. 27 (Berlin) pp. 469-505. (2019)

20. Madhwal Y, Panfilov P Blockchain And Supply Chain Management: Aircrafts' Parts' Business Case, Proceedings of the 28th DAAAM International Symposium (Vienna, Austria: DAAAM International) pp.1051-1056, (2017)

21. Hasan H R Salah K Blockchain-Based Proof of Delivery of Physical Assets With Single and Multiple Transporters IEEE Access, vol. 6, pp. 46781-46793. (2018)

22. Revin V, Shevcheko Y The opportunities and challenges of implementation of blockchain in aviation industry 4 (2) pp. 206-209. (2019)

23. Stathakopoulous C, Cachin C Threshold Signatures for Blockchain Systems (Zurich, Switzerland). (2017) 
24. Christidis K, Devetsikiotis M Blockchains and smart contracts for the internet of things Ieee Access, 4, 2292-2303. (2016)

25. Ream J, Chu Y, Schatsky D Upgrading blockchains: Smart contract use cases in industry Deloltte Univercity Press, 02 (04), pp. 1-11. (2016)

26. Xu L, Chen L, Gao Z, Chang Y, Iakovou E, Shi W Binding the Physical and Cyber Worlds: A Blockchain Approach for Cargo Supply Chain Security Enhancement IEEE Int. Symp. on Technologies for Homeland Security (Woburn, MA) pp. 1-5. (2018)

27. Dobrovnik M, Herold D M, Furst E Kummer S. Blockchain for and in logistics: what to adopt and where to start Logistics, 2, issue 3, p. 18. (2018)

28. Hackius N, Petersen M Blockchain in logistics and supply chain : trick or treat?.Proc. of the Hamburg International Conference of Logistics (HICL) 18 p. (2017)

29. Kshetri N Blockchain's roles in meeting key supply chain management objectives International Journal of Information Management, 39, pp. 80-89. (2018)

30. Erkan H, Erkip N K Collaborative decision making for air traffic management: A generic mathematical program for the rescheduling problem Computers \& Industrial Engineering 137, p. 106016.A. Mecke, I. Lee, J.R. Baker jr., M.M. Banaszak Holl, B.G. Orr, Eur. Phys. J. E 14, 7 (2019) 